\title{
Effects of Rosiglitazone on the Expression of PPAR-y and on the Production of IL-6 and IL-8 in Acute Lung Injury Model Using Human Pulmonary Epithelial Cells
}

\author{
Sung Kyoung Kim, Chan Kwon Park, Sook Young Lee, Jeong Sup Song, \\ Sung Hak Park, and Young Kyoon Kim* \\ Department of Internal Medicine, College of Medicine, The Catholic University of Korea, Seoul, South Korea
}

\begin{abstract}
Purpose: Peroxisome proliferator-activated receptor (PPAR)-y ligand is known to repress the expression of pro-inflammatory mediators. However, it is unclear how it affects PPAR-y expression and the inflammatory response in the human lung. We investigated the effects of rosiglitazone (synthetic PPAR-y ligand) on the PPAR-y expression and on the IL-6 and IL-8 production in acute lung injury model using human lung epithelial cells.

Methods: A549 and Beas-2B cells were pre-treated with rosiglitazone and/or BADGE (selective PPAR$\gamma$ antagonist) and then treated with media control or cytokine mixture including TNF- $\alpha, I L-1 \beta$, and IFN- $\gamma$. PPAR-y expression was analyzed in cell lysates by Western blot. IL-6 and IL-8 production was measured in the culture supernatants by ELISA.

Results: PPAR-y expression was identified in all experimental groups except for the control. The cytokine mixture-induced IL-6 and IL-8 production was significantly inhibited by pre-treatment with rosiglitazone $(P<0.01)$. However, this inhibitory effect of rosiglitazone was not reversed by BADGE.

Conclusion: These suggest that rosiglitazone induces the PPAR-y expression and it may inhibit the cytokine mixture-induced IL-6 and IL-8 production through the PPAR-y independent pathway. The inhibitory mechanisms of rosiglitazone on the cytokine mixture-induced IL-6 and IL-8 production in human alveolar, and bronchial epithelial cells remain to be further investigated.
\end{abstract}

Keywords: Rosiglitazone, PPAR-y expression, IL-6, IL-8, Acute lung injury 


\section{INTRODUCTION}

\section{Various cytokines and inflammatory} mediators participate in inflammatory response of acute lung injury (ALI). In the midst of them, interleukin (IL)-6 secreted from diverse cells in pulmonary tissue is involved in inflammatory response accompanied with tissue injury and IL-8 plays an important role in neutrophil infiltration into pulmonary tissue through its powerful chemotaxis to neutrophil [1]. In addition, although alveolar and bronchial epithelial cells are major target cells of inflammatory response of $\mathrm{ALI}$, they can act as effector cells secreting IL-6 and IL-8. Therefore, these two cells are pivotal in the pathophysiology of ALI [2,3].

Peroxisome proliferator-activated receptor (PPAR) which belong to the nuclear hormone receptor superfamily is a transcription factor activated by ligand [4]. To date, three major types of PPAR, encoded by separate genes, have been identified; they are PPAR- $\alpha$, $P P A R-\beta / \delta$, and PPAR- $\gamma$. PPAR is ubiquitously expressed throughout the body. PPAR- $\alpha$ is expressed in numerous metabolically active tissues including liver, heart, kidney, and skeletal muscles, intestine, and pancreas and is also detectable in lung, placenta, and adipose tissues [5,6]. PPAR-y is expressed mainly in adipose tissues and plays a role in differentiation of adipocytes [7]. PPAR-y is also expressed in airway smooth muscles, airway epithelial cells, and alveolar macrophages $[8,9]$. On the other hand, PPAR- $\beta / \delta$ is expressed in most tissues and its action is not well known $[5,10]$. The PPARs regulate gene expression in heterodimeric association with retinoid $X$ receptors (RXRs) to specific PPAR response elements in the promoter regions of specific target genes. It has been suggested that the functions of PPAR are restricted to lipid metabolism and maintenance of homeostasis [11]. But, recent studies reported that activation of PPAR controls not only cellular proliferation and activation but also inflammatory response [12]. It is now known that binding of ligand to PPAR-y inhibits inflammatory genes by regulating another transcriptional factor, such as NF-kB (nuclear factor kappa B) [13].

Since the finding that activation of PPAR-Y repressed the expression of inflammatory mediators [14], researches on the antiinflammatory effect of PPAR-y increased. The studies on the anti-inflammatory effect of PPAR using thiazolidinedione (PPAR- $Y$ ligand, TZD) as a drug that improves insulin resistance is actively in progress $[15,16]$. However, little is known about the antiinflammatory effect of PPAR from resident tissue cells, particularly human lung, in ALI model. Therefore, we sought to know if rosiglitazone (a synthetic PPAR-y ligand) could induce the expression of PPAR- $\gamma$, and also whether it had effect on IL-6 and IL-8 production, which are inflammatory mediators in ALI, when cells are stimulated by a cytokine mixture in human alveolar and bronchial epithelial cells.

\section{EXPERIMENTAL}

\section{Cell culture and preparation}

Human alveolar epithelial (A549) cells (Korean Cell Line Bank, Seoul, Korea) were cultured in RPMI 1640 (GIBCO) medium supplemented with L-glutamine (300 mg/L), $10 \%$ FBS (JRH Biosciences, Lenexa, KS, USA), $20 \mathrm{mM}$ HEPES (GIBCO, Carlsbad, CA, USA), sodium bicarbonate $(2000 \mathrm{mg} / \mathrm{L}$, GIBCO) and antibiotics (penicillin $100 \mathrm{U} / \mathrm{ml}$, streptomycin $100 \mu \mathrm{g} / \mathrm{ml}$, GIBCO). Human bronchial epithelial (Beas-2B) cells (American Type Culture Collection, Rockville, MD, USA) were cultured in DMEM/F12 (Sigma-Aldrich, St. Louis, MO, USA) medium supplemented with L-glutamine (365 mg/L), 10\% FBS (JRH Biosciences, Lenexa, KS, USA), $15 \mathrm{mM}$ HEPES (GIBCO, Carlsbad, CA, USA), sodium bicarbonate (1200 mg/L, GIBCO) and antibiotics (penicillin $100 \mathrm{U} / \mathrm{ml}$, streptomycin $100 \mu \mathrm{g} / \mathrm{ml}$, GIBCO).

To measure cell viability, $1 \times 10^{4}$ cells/well were seeded in 96-well culture plate. To examine the expression of PPAR-y and IL-6 
and $\mathrm{IL}-8$ production in $\mathrm{A} 549$ and Beas-2B cells, each cell was seeded in 6 -well culture plate at a density of $2 \times 10^{5}$ (A549) and $3 \times 10^{5}$ (Beas-2B) cells/well. These cell lines were cultured for 2 days, and then FBS concentration was reduced by twenty times from 10 to $0.5 \%$. The cells were treated with rosiglitazone (Alexis biochemicals, Plymouth Meeting, PA, USA) and bisphenol A diglycidyl ether (a selective PPAR-y antagonist, BADGE, Sigma-Aldrich) at various concentrations for $1 \mathrm{~h}$. After all the treatments, cytokine mixture [17] was added and after $24 \mathrm{~h}$, the cells were collected. In all the experiments, with the cells selected from the 4th subculture were used. The supernatant was harvested and kept at $-70{ }^{\circ} \mathrm{C}$ to measure IL-6 and IL-8 production.

To examine the expression of PPAR-y, the cell membranes were dissolved in lysis buffer [1\% Triton X-100, $1 \mathrm{mM}$ EGTA, $10 \mathrm{mM}$ Tris (pH 7.2), $1 \mathrm{mM}$ Benzamidine, $1 \mathrm{mM} \mathrm{Na}_{3} \mathrm{VO}_{4}$, $158 \mathrm{mM} \mathrm{NaCl}, 1 \%$ Sodium deoxycholate, and $0.1 \%$ SDS]. The collected cells were centrifuged at $13,000 \mathrm{rpm}$ for $15 \mathrm{~min}$. After the supernatant was discarded, the cells were kept at $-20{ }^{\circ} \mathrm{C}$.

\section{Classification of experimental groups}

The experimental groups were classified as follows: control group, cytokine mixture treatment group (CM), rosiglitazone treatment group (RSG), the group of cytokine mixture treatment after pre-treatment with rosiglitazone ( $\mathrm{RSG}+\mathrm{CM})$, and the group of cytokine mixture treatment after pretreatment with rosiglitazone and BADGE (RSG+BADGE+CM). The RSG+BADGE+CM group was subdivided into three groups according to the concentration of BADGE (5, 25, and $50 \mu \mathrm{M})$ (Table 1).

\section{Measurement of cell viability}

Cell viability was determined with MTT assay using Cell Counting Kit-8 (Dojindo Laboratories, Tokyo, Japan). Briefly, the cells were seeded in 96-well plates and treated as mentioned above. The samples were analyzed by an ELISA plate reader at $450 \mathrm{~nm}$ wavelength. Cell viability of the experimental groups was indicated as relative percentage to the control group.

Table 1: Classification of experimental groups

\begin{tabular}{|c|c|}
\hline $\begin{array}{l}\text { Group } 1 \\
\text { Group } 2\end{array}$ & $\begin{array}{l}\text { Control (medium only) } \\
\text { Medium } 1 \mathrm{hr}+\text { Cytokine mixture } 24 \mathrm{hrs}\end{array}$ \\
\hline Group 3 & $\begin{array}{l}\text { Rosiglitazone } 50 \mu \mathrm{M} 1 \mathrm{hr}+\text { Medium } \\
24 \mathrm{hrs}\end{array}$ \\
\hline Group 4 & $\begin{array}{l}\text { Rosiglitazone } 50 \mu \mathrm{M} 1 \mathrm{hr}+\text { Cytokine } \\
\text { mixture } 24 \mathrm{hrs}\end{array}$ \\
\hline Group 5 & $\begin{array}{l}\text { (Rosiglitazone } 50 \mu \mathrm{M}+\text { BADGE } 5 \mu \mathrm{M}) \\
1 \mathrm{hr}+\text { Cytokine mixture } 24 \mathrm{hrs}\end{array}$ \\
\hline Group 6 & $\begin{array}{l}\text { (Rosiglitazone } 50 \mu \mathrm{M}+\text { BADGE } 25 \\
\mu \mathrm{M}) 1 \mathrm{hr}+\text { Cytokine mixture } 24 \mathrm{hrs}\end{array}$ \\
\hline Group 7 & $\begin{array}{l}\text { (Rosiglitazone } 50 \mu \mathrm{M}+\text { BADGE } 50 \\
\mu \mathrm{M}) 1 \mathrm{hr}+\text { Cytokine mixture } 24 \mathrm{hrs}\end{array}$ \\
\hline $\begin{array}{l}\text { BADGE: } b \\
T N F-\alpha(4 n\end{array}$ & $\begin{array}{l}\text { sphenol A diglycidyl ether, Cytokine mixture } \\
\mathrm{g} / \mathrm{ml})+I L-1 \beta(1 \mathrm{ng} / \mathrm{ml})+I F N-y(10 \mathrm{ng} / \mathrm{ml})\end{array}$ \\
\hline
\end{tabular}

Rosiglitazone of $50 \mu \mathrm{M}$ was used to induce PPAR-y expression. To inhibit the ability of rosiglitazone to stimulate transcriptional activity of PPAR- $\gamma$, BADGE of 5,25 , and 50 $\mu \mathrm{M}$ was used. Rosiglitazone and BADGE were dissolved with DMSO (dimethylsulfoxide, Sigma-Aldrich). Expression of PPAR-y was measured by western blot analysis.

Protein content was quantified by Bradford assay using Coomassie plus protein assay reagent (Pierce, Rockford, IL, USA). Total proteins taken from each sample were loaded on $8 \%$ sodium dodecyl sulfate polyacrylamide gel and subjected to electrophoresis (SDSPAGE). After electrophoresis, proteins were transferred onto a PVDF membrane (Amersham Pharmacia Biotech, Buckinghamshire, UK) and blocked with $10 \%$ skim milk for 15 minutes. The membrane was incubated overnight with a primary antibody for mouse anti-PPAR-y monoclonal antibody (1:200, Santa Cruz Biotech, West Grove, PA, USA) at room temperature.

Trop J Pharm Res, December 2011;10 (6):733 
After washing three times with PBS, the membrane was incubated with a secondary antibody, Donkey anti-mouse IgG-HRP (1:1000, Santa Cruz Biotech) for 30 minutes at room temperature. Protein was detected by chemiluminescence with the ECL Western Blotting Analysis System (Amersham Pharmacia Biotech, Buckinghamshire, UK). The hybridized membranes were exposed to $X$-ray film (Amersham Pharmacia). The band intensity of PPAR- $y$ was measured with a densitometer. The expressed PPAR- $\gamma$ was indicated as relative percentage of $\beta$-actin (housekeeping protein).

Induction and measurement of IL-6 and IL8 production

Cytokine mixture (R\&D systems, Minneapolis, MN, USA) [17] was used to induce IL-6 and IL-8 production. The concentration of each cytokine in the mixture was $4 \mathrm{ng} / \mathrm{ml}$ (TNF- $\alpha), 1 \mathrm{ng} / \mathrm{ml}$ (IL-1 $\beta$ ), and 10 $\mathrm{ng} / \mathrm{ml}$ (IFN- $\mathrm{\gamma}$ ). After incubation for 24 hours, supernatants were harvested. The supernatants were diluted as follows; $1: 10$ and 1:50 for IL-6 from A549 and Beas-2B cells, 1:200 for IL-8 from A549 and Beas-2B cells. The supernatants concentration of IL- 6 and IL-8 was measured with Human ELISA set (BD biosciences Pharmingen, San Diego, CA, USA) following the manual. Lowest limit of measurement was $4.7 \mathrm{pg} / \mathrm{ml}$ for IL-6 and $3.1 \mathrm{pg} / \mathrm{ml}$ for IL-8. The average concentration of IL-6 and IL-8 was $4.7 \sim 300 \mathrm{pg} / \mathrm{ml}$ and $3.1 \sim 200 \mathrm{pg} / \mathrm{ml}$, respectively. Optical density was measured at $450 \mathrm{~nm}$ wavelength.

\section{Statistical analysis}

Statistical analysis was carried out by oneway analysis of variance (ANOVA) with a Bonferroni post-hoc test using SPSS version 12.0 for windows (SPSS Inc., Chicago, IL, USA). $P<0.05$ was considered to indicate statistical significance. All values were expressed as the mean \pm S.E.M.

\section{RESULTS}

There was no significant reduction in cell viability in all the experimental groups (Fig 1). Western blot analysis showed the expression of PPAR-y in all experimental groups except for the control (Fig 2).
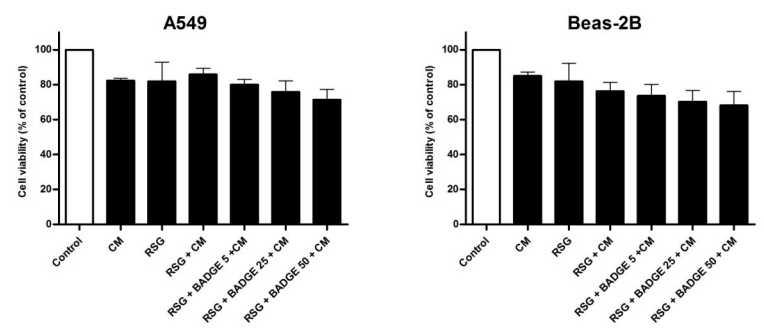

Fig 1: Effects of rosiglitazone, BADGE, and cytokine mixture on cell viability of A549 and Beas-2B cells. Note: Data are mean \pm S.E.M. from three independent experiments. RSG: rosiglitazone, BADGE: bisphenol $A$ diglycidyl ether, CM: cytokine mixture.
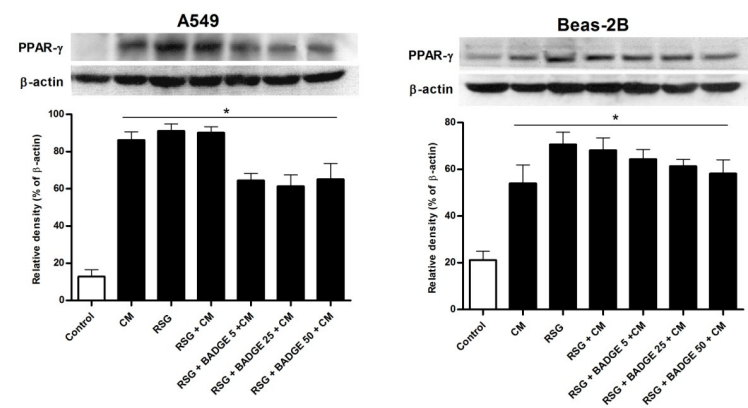

Fig 2: Expression of PPAR-y in A549 and Beas$2 \mathrm{~B}$ cells. Note: Data are mean \pm S.E.M. from three independent experiments. RSG: rosiglitazone, BADGE: bisphenol A diglycidyl ether, CM: cytokine mixture. ${ }^{*} P<0.01$ vs Control.

There was no significant difference in the degree of expression of PPAR-y between each experimental group except for the control. IL-6 and IL-8 production under stimulation with cytokine mixture was significantly increased compared with the control or rosiglitazone treatment (Figs 3 and 4). The increase in IL-6 and IL-8 production under stimulation with cytokine mixture was significantly decreased by pre-treatment with rosiglitazone. The rosiglitazone-mediated decrease of IL- 6 and IL-8 production was not 
reversed by co-treatment with PPAR-y antagonist, BADGE. All these findings were observed in both cell lines.

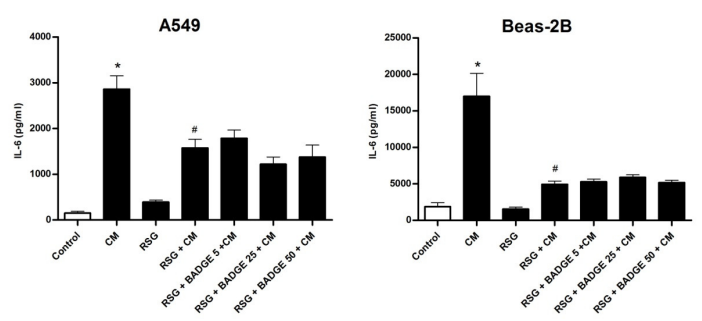

Fig 3: Effects of rosigiltazone and BADGE on cytokine mixture-induced IL-6 production in A549 and Beas-2B cells. Note: Data are mean \pm S.E.M. from three independent experiments. RSG: rosiglitazone, BADGE: bisphenol A diglycidyl ether, CM: cytokine mixture. ${ }^{*} P<0.01$ vs Control or RSG, \# P<0.01 vs CM.
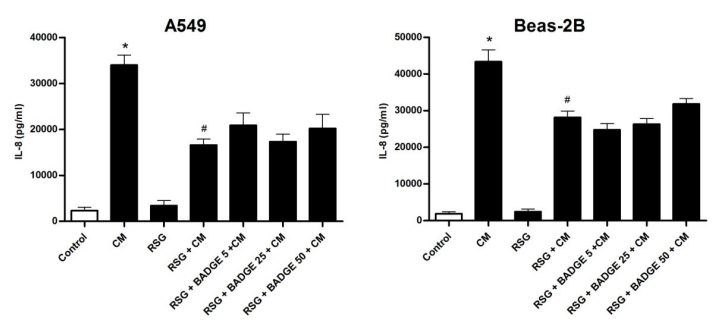

Fig 4: Effects of rosigiltazone and BADGE cytokine mixture-induced IL-8 production in A549 and Beas-2B cells. Note: Data are mean \pm S.E.M. from three independent experiments. RSG: rosiglitazone, BADGE: bisphenol A diglycidyl ether, CM: cytokine mixture. ${ }^{*} P<0.01$ vs Control or RSG, \# $P<0.01$ vs CM.

\section{DISCUSSION}

$\mathrm{ALI}$ is a severe respiratory disease progressing to acute respiratory distress syndrome (ARDS) unless proper and early treatment is performed [2]. A characteristic view in the pathophysiologic mechanism of $A L I$ is that it is a neutrophil-dependent lung injury. Numerous cytokines secreted from activated alveolar macrophages play a crucial role in the chemotaxis and activation of neutrophils, and various pro-inflammatory materials secreted from this activated neutrophils work in a complex way and participate in the lung injury $[3,18,19]$.
Following recent interest in inflammatory cytokines secreted from activated neutrophils, several efforts to develop new drugs for $\mathrm{ALI}$ are ongoing. In particular, researches on anti-inflammatory effects using PPAR ligand have increased.

Since it is known that PPAR has an important function in the control energy homeostasis and inflammatory response, some studies using various synthetic PPAR ligands have been reported. Many clinical investigations using these synthetic ligands including rosiglitazone, pioglitazone, and troglitazone, are under way. For example, Liu et al reported that rosiglitazone significantly reduced endotoxin-induced $A L I$ in rats [20]. Also, Ito et al showed that pre-treatment with pioglitazone, a PPAR- $\gamma$ agonist, before ischemia attenuated lung ischemiareperfusion injury in rats [21]. On the contrary, Inoue et al disclosed that 15-deoxy$\Delta^{12,14}$-prostaglandin $\mathrm{J}_{2}\left(15 \mathrm{~d}-\mathrm{PG} \mathrm{J}_{2}\right)$, a PPAR-y ligand, did not improve but significantly enhanced ALI induced by lipopolysaccharide in the mouse [22].

In our study, we identified that rosiglitazone could directly induce the expression of PPAR-y in alveolar and bronchial epithelial cells, resident tissue cells of lung. This finding is in agreement with the previous in vitro study $[8,9]$. One interesting finding is that the cytokine mixture itself induced the expression of PPAR-y in both cell lines. It may be associated with a part of the natural defensive mechanism against external insult.

Regarding the effects on IL-6 and IL-8 production, treatment with the cytokine mixture increased IL-6 and IL-8 production compared with the control group in both cell lines. The increase of $\mathrm{IL}-6$ and $\mathrm{IL}-8$ production by treatment with the cytokine mixture was significantly decreased by pretreatment with rosiglitazone. However, when they were simultaneously treated with rosiglitazone and BADGE, decrease of IL-6 and IL-8 production by pre-treatment with rosiglitazone was not reversed. These results 
suggest that there may be a PPAR- $\gamma$ independent pathway on anti-inflammatory effects of rosiglitazone in human alveolar and bronchial epithelial cells.

In fact, there are several other reports in agreement with our results.

Hinz et al delineated a PPAR-y independent inhibitory action of $15 \mathrm{~d}-\mathrm{PGJ}_{2}$ on the expression of several pro-inflammatory genes in LPS-induced human blood monocytes, and also showed that it was not reversed by BADGE [23]. In addition, Chawla et al identified that the inhibitory ability of $15 \mathrm{~d}$ $P G J_{2}$ and various TZDs on the proinflammatory cytokines secreted from wildtype macrophages treated with LPS was equally effective in PPAR-y-deficient macrophages [24], emphasizing that the inhibitory effect of $15 d-P G J_{2}$ and various TZDs on inflammatory cytokine production may be receptor independent.

Although these studies showed the PPAR-y independent pathway of PPAR-y ligand, few reports on PPAR-y independent pathway of rosiglitazone in inflammatory models has been demonstrated until now. Seargent et al documented that the anticancer effect of rosiglitazone was not reversed by GW9662, a PPAR-y antagonist, in brest tumor cells [25]. This means that the growth inhibition of tumor cells induced by rosiglitazone occurs independent of PPAR- $\gamma$ activation. In addition, Derlacz et al reported PPAR-y independent inhibitory effect of rosiglitazone on glucose synthesis in primary cultured rabbit kidney-cortex tubules [26]. Even if there were more studies suggesting PPAR- $y$ independent pathway of rosiglitazone, almost all the studies were performed in noninflammatory models. From this viewpoint, our study may be the first study implying PPAR-y independent anti-inflammatory effect of rosiglitazone in resident tissue cells, particularly human lung.

There were several studies suggesting a mechanism of PPAR- $y$ independent pathway of PPAR-y ligand in detail. A change of intracellular $\mathrm{pH}$ concentration may explain a mechanism of PPAR-y independent pathway [27]. Turturro et al that showed that troglitazone inhibited cellular proliferation through intracellular acidosis and blockage of DNA synthesis in breast cancer-derived cell lines. It was identified that troglitazonemediated inhibition of cellular proliferation was not reversed by the presence of the PPAR-y inhibitor GW9662 and was demonstrable in PPAR- $\gamma$-deficient cells, consistent with a PPAR-y independent mechanism. According to other recent studies, it has been reported that mitochondria play important role on the PPAR-y independent pathway of PPAR-y ligand.

Pérez et al reported PPAR-y independent cytotoxicity of ciglitazone in astrogial cells [28]. It suggests that the production of reactive oxygen species (ROS) and the rapid loss of mitochondrial membrane potential in astroglial cells may explain the PPAR-y independent pathway on the cytotoxicity of ciglitazone. Therefore, they indicated that ROS had a key role in glitazone cytotoxity and the mitochondria were a likely source of ROS and early targets of it. Scatena et al reported that PPAR-Y ligands inhibited $\mathrm{NADH}$-cytochrome $\mathrm{c}$ reductase activity and induced the derangement of mitochondrial respiratory chain from HP-60 (human acute promyelocytic leukemia) cell lines, suggesting a non-receptor-mediated effect of synthetic PPAR-ligands [29]. In addition, recent study has demonstrated a novel binding site (termed "mitoNEET") of glitazones in mitochondria, using tritiated pioglitazone and a photoaffinity cross-linker [30].

Although additional studies may be required, these reports mentioned above and the outcome of this study could raise the intriguing possibility that rosiglitazone may have another pathway, not PPAR-y, in human pulmonary epithelial cells. 


\section{CONCLUSION}

Our in vitro investigation demonstrated that rosiglitazone, a PPAR-y agonist, possesses anti-inflammatory properties in human pulmonary epithelial cells. This provides an evidence for the therapeutic potential of rosiglitazone in the treatment of ALI. Judging from the effect of BADGE on the antiinflammatory action of rosiglitazone, it is postulated that rosiglitazone could have an anti-inflammatory effect via a PPAR-y independent pathway. However, further investigation will be needed to characterize the exact PPAR-y independent pathway of rosiglitazone in human pulmonary epithelial cells.

\section{ACKNOWLEDGEMENT}

This study was supported, in part, by research funds from Catholic Medical Center of Korea. We thank Jin Sook Kim for expert technical assistance throughout the study.

\section{REFERENCES}

1. Schutte H, Lohmeyer J, Rosseau S, Ziegler S, Siebert $\mathrm{C}$, Kielisch $\mathrm{H}$, Pralle $\mathrm{H}$, Grimminger $\mathrm{F}$, Morr $\mathrm{H}$, Seeger W. Bronchoalveolar and systemic cytokine profiles in patients with ARDS, severe pneumonia and cardiogenic pulmonary oedema. Eur Respir J 1996; 9: 1858-1867.

2. Ware $L B$, Matthay MA. The acute respiratory distress syndrome. N Engl J Med 2000; 342: 13341349.

3. Suratt BT, Parsons PE. Mechanisms of acute lung injury/acute respiratory distress syndrome. Clin Chest Med 2006; 27: 579-589; abstract viii.

4. Evans RM. The steroid and thyroid hormone receptor superfamily. Science 1988; 240: 889-895.

5. Braissant O, Foufelle F, Scotto C, Dauca M, Wahli W. Differential expression of peroxisome proliferator-activated receptors (PPARs): tissue distribution of PPAR-alpha, -beta, and gamma in the adult rat. Endocrinology 1996; 137: 354-366.

6. Escher P, Wahli W. Peroxisome proliferator-activated receptors: insight into multiple cellular functions. Mutat Res 2000; 448: 121-138.

7. Spiegelman BM, Flier JS. Adipogenesis and obesity: rounding out the big picture. Cell 1996; 87: 377-389.

8. Pawliczak $R$, Han $C$, Huang $X L$, Demetris AJ, Shelhamer JH, Wu T. 85-kDa cytosolic phospholipase A2 mediates peroxisome proliferator-activated receptor gamma activation in human lung epithelial cells. J Biol Chem 2002; 277: 33153-33163.

9. Wang AC, Dai X, LuU B, Conrad DJ. Peroxisome proliferator-activated receptor-gamma regulates airway epithelial cell activation. $A m \mathrm{~J}$ Respir Cell Mol Biol 2001; 24: 688-693.

10. Kliewer SA, Forman BM, Blumberg B, Ong ES, Borgmeyer U, Mangelsdorf DJ, Umesono K, Evans RM. Differential expression and activation of a family of murine peroxisome proliferator-activated receptors. Proc Natl Acad Sci U S A 1994; 91: 7355-7359.

11. Green S. PPAR: a mediator of peroxisome proliferator action. Mutat Res 1995; 333: 101109.

12. Vamecq J, Latruffe N. Medical significance of peroxisome proliferator-activated receptors. Lancet 1999; 354: 141-148.

13. Bailey ST, Ghosh S. 'PPAR'ting ways with inflammation. Nat Immunol 2005; 6: 966-967.

14. Ricote M, Li AC, Willson TM, Kelly CJ, Glass CK. The peroxisome proliferator-activated receptor-gamma is a negative regulator of macrophage activation. Nature 1998; 391: 7982.

15. Cuzzocrea $S$, Pisano $B$, Dugo $L$, lanaro $A$, Maffia $P$, Patel NS, Di Paola R, lalenti A, Genovese T, Chatterjee PK, et al. Rosiglitazone, a ligand of the peroxisome proliferator-activated receptorgamma, reduces acute inflammation. Eur $J$ Pharmacol 2004; 483: 79-93.

16. Abdelrahman $M$, Sivarajah $A$, Thiemermann $C$. Beneficial effects of PPAR-gamma ligands in ischemia-reperfusion injury, inflammation and shock. Cardiovasc Res 2005; 65: 772-781.

17. Liaudet L, Mabley JG, Pacher P, Virag L, Soriano FG, Marton A, Hasko G, Deitch EA, Szabo C. Inosine exerts a broad range of antiinflammatory effects in a murine model of acute lung injury. Ann Surg 2002; 235: 568578

18. Martin MA, Silverman HJ. Gram-negative sepsis and the adult respiratory distress syndrome. Clin Infect Dis 1992; 14: 1213-1228.

19. Welbourn CR, Young Y. Endotoxin, septic shock and acute lung injury: neutrophils, macrophages and inflammatory mediators. $\mathrm{Br}$ J Surg 1992; 79: 998-1003.

20. Liu D, Zeng BX, Zhang SH, Wang YL, Zeng L, Geng ZL, Zhang SF. Rosiglitazone, a peroxisome proliferator-activated receptor-gamma agonist, reduces acute lung injury in endotoxemic rats. Crit Care Med 2005; 33: 2309-2316.

21. Ito K, Shimada J, Kato D, Toda S, Takagi T, Naito $Y$, Yoshikawa T, Kitamura N. Protective effects of preischemic treatment with pioglitazone, a peroxisome proliferator-activated receptorgamma ligand, on lung ischemia-reperfusion injury in rats. Eur J Cardiothorac Surg 2004; 25: $530-536$

22. Inoue $K$, Takano $H$, Yanagisawa $R$, Ichinose $T$, Sadakane K, Yoshino S, Yamaki K, Uchiyama 
K, Yoshikawa T. Effects of 15-deoxyDelta12,14-prostaglandin J2 on the expression of Toll-like receptor 4 and 2 in the murine lung in the presence of lipopolysaccharide. Clin Exp Pharmacol Physiol 2005; 32: 230-232.

23. Hinz B, Brune K, Pahl A. 15-Deoxy-Delta(12,14)prostaglandin $\mathrm{J} 2$ inhibits the expression of proinflammatory genes in human blood monocytes via a PPAR-gamma-independent mechanism. Biochem Biophys Res Commun 2003; 302: 415-420.

24. Chawla A, Barak Y, Nagy L, Liao D, Tontonoz $P$, Evans RM. PPAR-gamma dependent and independent effects on macrophage-gene expression in lipid metabolism and inflammation. Nat Med 2001; 7: 48-52.

25. Seargent JM, Yates EA, Gill JH. GW9662, a potent antagonist of PPARgamma, inhibits growth of breast tumour cells and promotes the anticancer effects of the PPARgamma agonist rosiglitazone, independently of PPARgamma activation. Br J Pharmacol 2004; 143: 933937.

26. Derlacz RA, Hyc K, Usarek M, Jagielski AK, Drozak $J$, Jarzyna R. PPAR-gamma-independent inhibitory effect of rosiglitazone on glucose synthesis in primary cultured rabbit kidney- cortex tubules. Biochem Cell Biol 2008; 86 : 396-404.

27. Turturro F, Friday E, Fowler $R$, Surie $D$, Welbourne $T$. Troglitazone acts on cellular $\mathrm{pH}$ and DNA synthesis through a peroxisome proliferatoractivated receptor gamma-independent mechanism in breast cancer-derived cell lines. Clin Cancer Res 2004; 10: 7022-7030.

28. Perez-Ortiz JM, Tranque $P$, Vaquero CF, Domingo $B$, Molina F, Calvo S, Jordan J, Cena V, Llopis $J$. Glitazones differentially regulate primary astrocyte and glioma cell survival. Involvement of reactive oxygen species and peroxisome proliferator-activated receptor-gamma. J Biol Chem 2004; 279: 8976-8985.

29. Scatena $R$, Bottoni $P$, Martorana GE, Ferrari $F, D e$ Sole $P$, Rossi C, Giardina B. Mitochondrial respiratory chain dysfunction, a non-receptormediated effect of synthetic PPAR-ligands: biochemical and pharmacological implications. Biochem Biophys Res Commun 2004; 319: 967-973.

30. Colca JR, McDonald WG, Waldon DJ, Leone JW, Lull JM, Bannow CA, Lund ET, Mathews WR. Identification of a novel mitochondrial protein ("mitoNEET") cross-linked specifically by a thiazolidinedione photoprobe. Am J Physiol Endocrinol Metab 2004; 286: E252-260. 